\title{
ANALISA STRUKTUR DAN METODE PELAKSANAAN KOLOM DAN BALOK PADA PEMBANGUNAN GEDUNG APD PLN MEDAN
}

\author{
Lukas Mawira P. Kuswinardi ${ }^{1}$, Reskina T.A Sinurat ${ }^{2}$, Palghe Tobing ${ }^{3}$ \\ ${ }^{1}$ Program Studi Manajemen Rekayasa Konstruksi Gedung, Politeknik Negeri Medan \\ Email: lukasmawira@students.polmed.ac.id \\ ${ }^{2}$ Program Studi Manajemen Rekayasa Konstruksi Gedung, Politeknik Negeri Medan \\ ${ }^{3}$ Program Studi Manajemen Rekayasa Konstruksi Gedung, Politeknik Negeri Medan
}

\begin{abstract}
Abstrak. Dalam perencanaan struktur beton bertulang, diperlukan suatu kepastian tentang keamanan struktur terhadap keruntuhan yang mungkin terjadi selama umur bangunan. Berbagai hal perlu ditinjau yang meliputi beberapa kriteria, yaitu kekuatan, kekakuan, dan kemampuan menerima beban, sehingga diperoleh kekuatan yang optimum. Penelitian ini mengacu kepada aturan Standar Nasional Indonesia (SNI), diantaranya SNI 1726:2012, SNI 1727:2013, serta SNI 2847:2013. Analisis struktur pada penelitian ini dilakukan dengan bantuan program komputer SAP2000 v.14. Analisis dilakukan dengan pemodelan 3 dimensi, kemudian didapatkan momen ultimit serta beban aksial ultimit yang akan membantu dalam perencanaan tulangan balok dan kolom yang aman untuk bangunan. Adapun hasil dari penulisan tugas akhir ini yaitu dimensi dan jumlah tulangan sudah memenuhi persyaratan, dimana untuk balok $\emptyset \mathrm{Mn}>\mathrm{Mu}$, dan untuk kolom $\varnothing \mathrm{Mn}>\mathrm{Mu}, \varnothing \mathrm{Pn}>\mathrm{Pu}$ serta metode pelaksanaan yang dilakukan pada pekerjaan kolom dan balok telah sesuai dengan standar metode pelaksanaan pekerjaan struktur.
\end{abstract}

Kata kunci: Beton Bertulang, Balok, Kolom, Sap2000, Pelaksanaan Konstruksi

Diterima Redaksi: 03-10-2020 | Selesai Revisi: 08-03-2021 | Diterbitkan Online: 09-03-2021

\section{PENDAHULUAN}

Kota Medan secara geografis berada diatas permukaan laut dengan kondisi tanah yang mempunyai daya dukung tanah memadai untuk pembangunan bangunan bertingkat banyak (multy-stories building). Seiring dengan kemajuan teknologi bangunan bertingkat banyak dan semakin terbatasnya lahan untuk tempat bangunan, maka perlu ada pemanfaatan lahan semaksimal mungkin, salah satu alternatif yang diambil adalah dengan pembuatan bangunan bertingkat banyak seperti pada proyek pembangunan Gedung Kantor APD (Area Pengatur Distribusi) PLN Jalan KL Yos Sudarso No. 284, Glugur Kota, Wilayah Sumatera Utara, Medan dengan jumlah tingkat 5 lantai.

Dalam merencanakan suatu gedung bertingkat tentunya harus diperhatikan beberapa unsur utama, meliputi unsur: keindahan, kenyamanan, kekuatan, serta nilai ekonomis dari pembangunan gedung tersebut. Salah satu faktor yang paling berpengaruh dalam perencanaan struktur bangunan bertingkat tinggi adalah kekuatan struktur bangunan, dimana faktor ini sangat terkait dengan keamanan dan ketahanan bangunan dalam menahan atau menampung beban yang bekerja pada struktur. Indonesia termasuk negara rawan dilanda gempa karena terletak di pertemuan lempeng pasifik dan asia. Menurut SNI 03-1726-2002, Medan termasuk pada wilayah gempa zona 3 yaitu daerah yang cukup besar kemungkinan terjadinya gempa. 
Di Indonesia, peraturan atau pedoman standar yang mengatur tata cara perhitungan struktur beton untuk bangunan adalah Persyaratan Beton Struktural Untuk Bangunan Gedung SNI 2847:2013. Peraturan pembebanan yang digunakan dalam perencanaan beton bertulang ialah Peraturan Pembebanan Indonesia Untuk Gedung 1983, Beban Minimum untuk Perancangan Bangunan Gedung dan Struktur Lain SNI 1727:2013.

Analisis struktur adalah suatu proses dimana engineer menentukan respons suatu struktur terhadap suatu pembebanan. Respons struktur dinyatakan dengan gaya-gaya yang terjadi didalam struktur dan deformasi yang dialami dan gaya gaya dalam tersebutlah yang akan digunakan dalam perencanaan struktur pada gedung. Oleh karena itu diperlukan analisis dan desain serta metode pelaksanaan yang tepat agar dapat digunakan sebaik-baiknya.

Pelaksanaan analisis struktur dapat dilakukan dengan dua cara, yaitu analisis struktur secara manual maupun dengan menggunakan bantuan program komputer. Untuk lebih mempermudah perhitungan struktur serta menghemat waktu dan tenaga, maka dalam penelitian ini digunakan salah satu program komputer yaitu SAP2000 v.14. Adapun tujuan yang akan dicapai pada pelaksanaan penelitian ini adalah untuk mengetahui hasil analisis, perencanaan dan metode pelaksanaan struktur kolom dan balok beton bertulang yang aman dan tepat pada pembangunan gedung APD PLN Medan.

\section{METODE PENELITIAN}

Adapun tahapan yang akan dilakukan pada pembuatan penelitian ini disajikan diagram alir penelitian seperti Gambar 1 berikut.

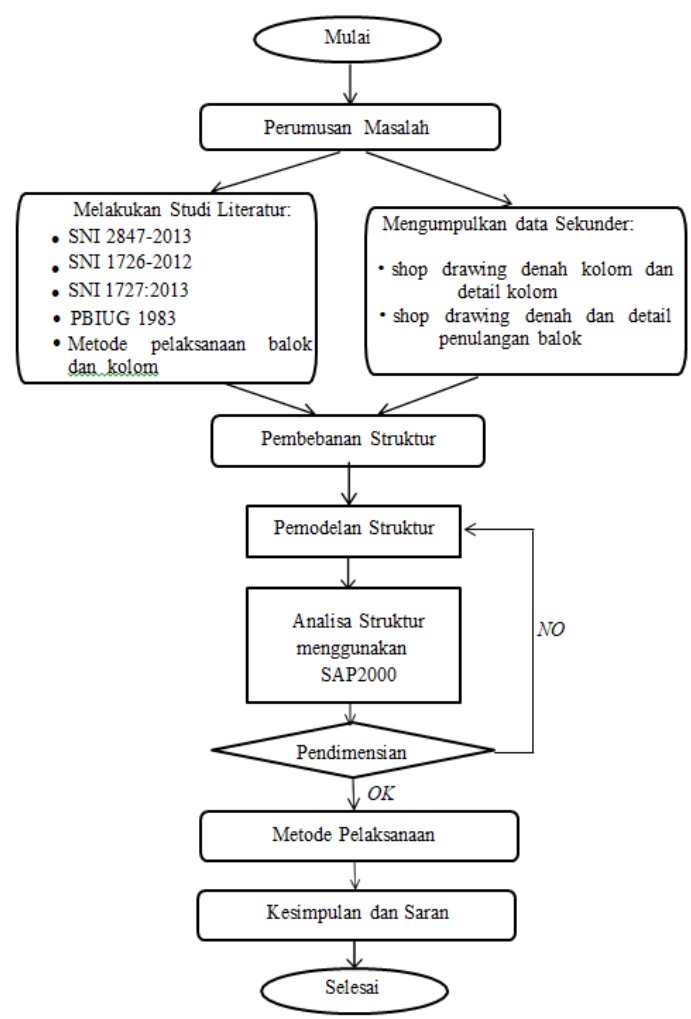

Gambar 1. Diagram alir pelaksanaan penelitian 


\section{HASIL DAN PEMBAHASAN}

\section{Pembebanan}

\section{Beban Mati}

Ada dua jenis beban mati yang bekerja yaitu beban mati pada balok dan beban mati pada pelat lantai. Beban mati yang terdapat pada gedung kantor APD PLN sebagai berikut :

1. Perhitungan beban mati pada lantai 2,3,4 dan 5:

$\begin{array}{lll}\text { Spesi setebal } 1 \mathrm{~cm} & =1 \times 21 \mathrm{Kg} / \mathrm{m}^{2} & =21 \mathrm{Kg} / \mathrm{m}^{2} \\ \text { Keramik } & =24 \mathrm{Kg} / \mathrm{m}^{2} & =24 \mathrm{Kg} / \mathrm{m}^{2} \\ M E & =25 \mathrm{Kg} / \mathrm{m}^{2} & =25 \mathrm{Kg} / \mathrm{m}^{2} \\ \text { Plafond } & =20 \mathrm{Kg} / \mathrm{m}^{2} & =20 \mathrm{Kg} / \mathrm{m}^{2} \\ \text { Total } & & =90 \mathrm{Kg} / \mathrm{m}^{2}\end{array}$

2. Perhitungan beban mati pada balok lantai 2:

Dinding bata $1 / 2$ batu

$$
\begin{aligned}
& =4,25 \mathrm{~m} \times 250 \mathrm{Kg} / \mathrm{m}^{2}=1062,5 \mathrm{Kg} / \mathrm{m} \\
& =4,25 \mathrm{~m} \times 60 \mathrm{Kg} / \mathrm{m}^{2}=255 \mathrm{Kg} / \mathrm{m}
\end{aligned}
$$

Curtain wall

3. Perhitungan beban mati pada balok lantai 3:

$$
\begin{array}{lll}
\text { Dinding bata } 1 / 2 \text { batu } & =4,25 \times 250 \mathrm{Kg} / \mathrm{m}^{2} & =1062,5 \mathrm{Kg} / \mathrm{m} \\
\text { Curtain wall } & =4,25 \mathrm{~m} \times 60 \mathrm{Kg} / \mathrm{m}^{2}= & 255 \mathrm{Kg} / \mathrm{m}
\end{array}
$$

4. Perhitungan beban mati pada balok lantai 4 :

$$
\begin{array}{ll}
\text { Dinding bata } 1 / 2 \text { batu } & =4,65 \times 250 \mathrm{Kg} / \mathrm{m}^{2} \quad=1162,5 \mathrm{Kg} / \mathrm{m} \\
\text { Curtain wall } & =4,65 \mathrm{~m} \times 60 \mathrm{Kg} / \mathrm{m}^{2}=279 \mathrm{Kg} / \mathrm{m}
\end{array}
$$

5. Perhitungan beban mati pada balok lantai 5:
Dinding bata $1 / 2$ batu (tangga)
$=2,8 \mathrm{~m} \times 250 \mathrm{Kg} / \mathrm{m}^{2} \quad=700 \mathrm{Kg} / \mathrm{m}$
Dinding bata $1 / 2$ batu (pagar atap) $\quad=1,7 \mathrm{~m} \times 250 \mathrm{Kg} / \mathrm{m}^{2} \quad=425 \mathrm{Kg} / \mathrm{m}$
Dinding bata $1 / 2$ batu (atap) $\quad=0,4 \mathrm{~m} \times 250 \mathrm{Kg} / \mathrm{m}^{2} \quad=100 \mathrm{Kg} / \mathrm{m}$

\section{Beban Hidup}

Beban hidup yang terdapat pada gedung kantor APD PLN sebagai berikut:

1. Beban hidup pada lantai kantor $=240 \mathrm{Kg} / \mathrm{m}^{2}$

2. Beban hidup pada atap $\quad=96 \mathrm{Kg} / \mathrm{m}^{2}$

\section{Beban Angin}

Perhitungan beban angin pada gedung kantor APD PLN adalah:

$\mathrm{V}: 40 \mathrm{~m} / \mathrm{s}(\mathrm{HB} 212-2002)$

Kz: 0,85 (SNI 1727-2013, Tabel 27.3-1)

Kd: 0.85 (SNI 1727-2013, Tabel 26.6-1)

Kzt : 1 (SNI 1727-2013, Pasal 26.8.2) 
$\mathrm{qh}=0,613 \times \mathrm{V}^{2} \times \mathrm{Kz} \times \mathrm{Kd} \times \mathrm{Kzt}$

$$
\begin{aligned}
& =0,613 \times 40^{2} \times 0,85 \times 0,85 \times 1 \\
& =733,638 \mathrm{~N} / \mathrm{m}^{2}
\end{aligned}
$$

G : 0,85 (SNI 1727-2013, Pasal 26.9.1)

Cp : 0,8 (SNI 1727-2013, Gambar 27.4-1)

Gcpi : 0,18 (SNI 1727-2013, Tabel 26.11.1)

$$
\begin{aligned}
\mathrm{p} & =\mathrm{qh} \times(\mathrm{GCp}-\mathrm{Gcpi}) \\
& =733,638 \times(0,85 \times 0,8-0,18) \\
& =366,819 \mathrm{~N} / \mathrm{m}^{2} \\
& =36,7 \mathrm{Kg} / \mathrm{m}^{2}
\end{aligned}
$$

\section{Beban Gempa}

Bangunan Gedung Kantor APD PLN berada pada lintang 3³6'55” dan bujur 9840'21". Dari situs puskim.pu.go.id, didapat parameter-parameter yang ditunjukkan pada Tabel 1 untuk menentukan nilai spektra bangunan pada tanah sedang (Gambar 2):

Tabel 1. Variabel Parameter Respon spektra

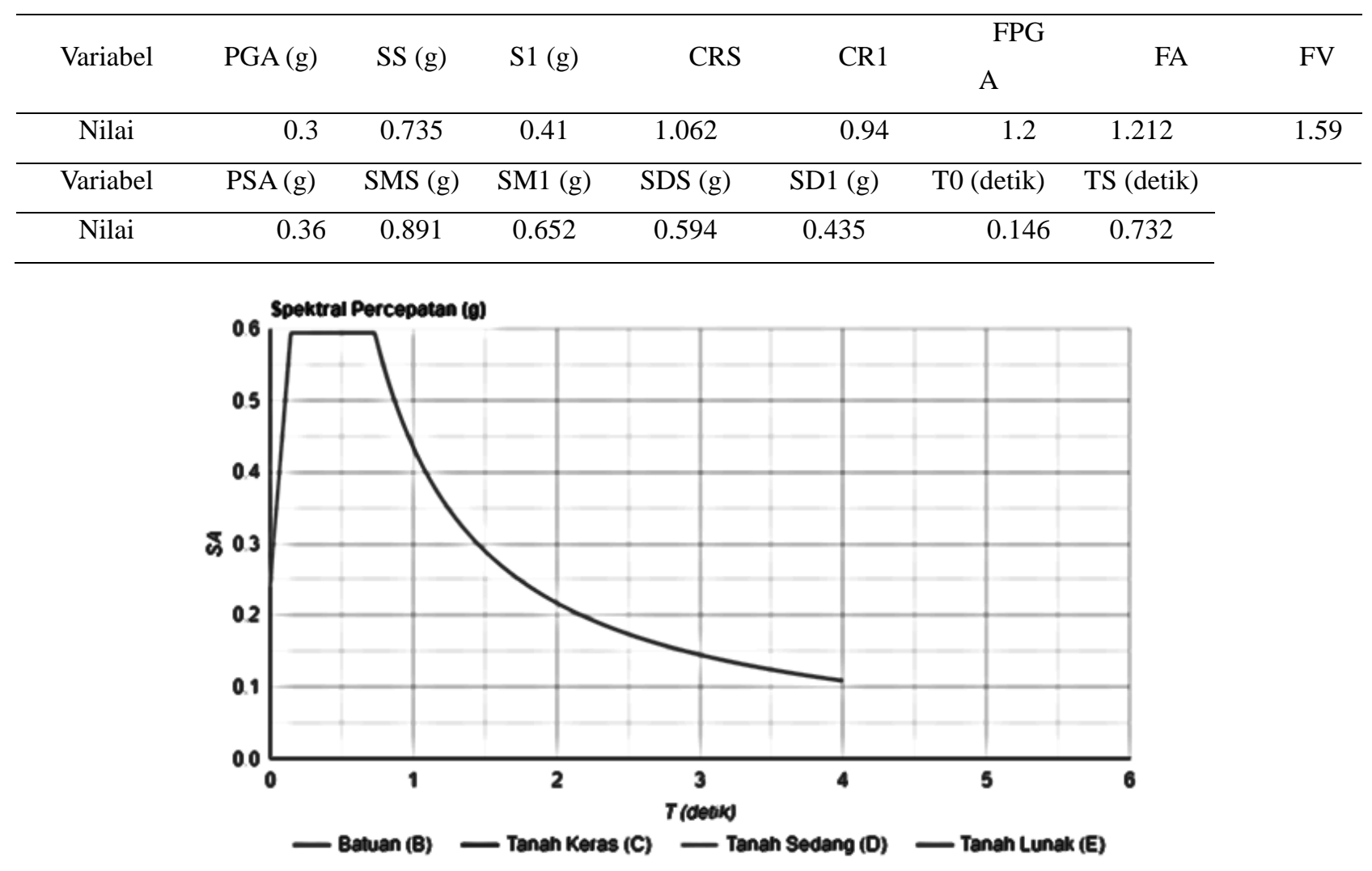

Gambar 2. Grafik respon spectrum tanah sedang

\section{Pemodelan dan Analisis Struktur}

Material-material yang akan digunakan: 
1. Beton F'c 25

Berat jenis : $2400 \mathrm{~kg} / \mathrm{m}^{3}$

F'c $\quad: 25 \mathrm{MPa}$

E $: 4700 \sqrt{f^{\prime} c}$

2. Baja Tulangan U39

Berat jenis : $7850 \mathrm{~kg} / \mathrm{m}^{3}$

fy $\quad: 390 \mathrm{MPa}$

fu $\quad: 560 \mathrm{MPa}$

E $\quad: 200000 \mathrm{MPa}$

3. Baja Tulangan U24

Berat jenis : $7850 \mathrm{~kg} / \mathrm{m}^{3}$

fy $\quad: 240 \mathrm{MPa}$

fu $\quad: 320 \mathrm{MPa}$

E : $200000 \mathrm{MPa}$

Penampang kolom dan balok yang akan diatur dalam penelitian ini:

Tipe-tipe balok:

1. $B 1(m)=0,3 \times 0,6$

2. $B 2(\mathrm{~m})=0,25 \times 0,40$

3. $\mathrm{B} 3(\mathrm{~m})=0,15 \times 0,2$

4. $\operatorname{RB} 1(m)=0,2 \times 0,3$

5. $\mathrm{RB} 2(\mathrm{~m})=0,15 \times 0,15$

Tipe-tipe kolom:

1. $\mathrm{K} 1(\mathrm{~m})=0,3 \times 0,5$

2. $\mathrm{K} 2(\mathrm{~m})=0,2 \times 0,2$

3. $\mathrm{KP}(\mathrm{m})=0,15 \times 0,15$

Setelah pemodelan dan penerapan beban pada setiap penampang, maka dilakukan analisis terhadap model struktur. Hasil analisis yang digunakan untuk penelitian ini berupa gaya dalam. Gaya dalam tersebut akan digunakan untuk menentukan luas tulangan perlu untuk setiap penampang, sehingga didapatkan jumlah tulangan yang akan digunakan pada kolom maupun balok.

Perencanaan Penulangan

Perencanaan Penulangan Pada Balok (Tabel 2)

Tabel 2. Hasil Analisis Dan Dimensi Tulangan Balok

\begin{tabular}{|c|c|c|c|c|c|c|c|}
\hline \multirow{2}{*}{ Lantai } & \multirow{2}{*}{$\begin{array}{l}\text { Type } \\
\text { Balok }\end{array}$} & \multirow{2}{*}{$\begin{array}{l}\text { Dimensi } \\
(\mathrm{mm})\end{array}$} & \multirow{2}{*}{\multicolumn{2}{|c|}{$\mathrm{Mu}(\mathrm{kNm})$}} & \multicolumn{2}{|c|}{ Jumlah Tulangan } & \multirow{2}{*}{$\begin{array}{l}\phi \mathrm{Mn} \\
(\mathrm{kNm})\end{array}$} \\
\hline & & & & & Tekan & Tarik & \\
\hline \multirow{2}{*}{2} & \multirow{2}{*}{ B1 } & \multirow{2}{*}{$300 \times 600$} & Tumpuan & 231.4 & $2 \mathrm{D} 19$ & $5 \mathrm{D} 19$ & 249.34 \\
\hline & & & Lapangan & 150.1 & 2D19 & 5D19 & 249.34 \\
\hline
\end{tabular}


JURNAL ILMIAH TEKNIK SIPIL AGREGAT

VDL. 1, ND. 1, (2DZ1) EDISI MEI, 6 - 14

Tabel 2. Hasil Analisis Dan Dimensi Tulangan Balok

\begin{tabular}{|c|c|c|c|c|c|c|c|}
\hline \multirow{4}{*}{ Lantai } & \multirow{4}{*}{$\begin{array}{c}\text { Type } \\
\text { Balok } \\
\text { B2 }\end{array}$} & \multirow{4}{*}{$\begin{array}{l}\begin{array}{c}\text { Dimensi } \\
(\mathrm{mm})\end{array} \\
250 \times 400\end{array}$} & \multirow{2}{*}{\multicolumn{2}{|c|}{$\mathrm{Mu}(\mathrm{kNm})$}} & \multicolumn{2}{|c|}{ Jumlah Tulangan } & \multirow{3}{*}{$\begin{array}{r}\begin{array}{r}\varnothing \mathrm{Mn} \\
(\mathrm{kNm})\end{array} \\
86.27\end{array}$} \\
\hline & & & & & \multirow{2}{*}{$\begin{array}{l}\text { Tekan } \\
\text { 2D16 }\end{array}$} & \multirow{2}{*}{$\begin{array}{l}\text { Tarik } \\
\text { 4D16 }\end{array}$} & \\
\hline & & & Tumpuan & 49.65 & & & \\
\hline & & & Lapangan & 46.17 & 2D16 & 4D16 & 86.27 \\
\hline \multirow{4}{*}{3} & \multirow{2}{*}{ B1 } & \multirow{2}{*}{$300 \times 600$} & Tumpuan & 195.8 & 2D19 & $5 \mathrm{D} 19$ & 249.34 \\
\hline & & & Lapangan & 140.7 & 2D19 & 5D19 & 249.34 \\
\hline & \multirow{2}{*}{ B2 } & \multirow{2}{*}{$250 \times 400$} & Tumpuan & 51.89 & 2D16 & 4D16 & 86.27 \\
\hline & & & Lapangan & 44.59 & 2D16 & 4D16 & 86.27 \\
\hline \multirow{4}{*}{4} & \multirow{2}{*}{ B1 } & \multirow{2}{*}{$300 \times 600$} & Tumpuan & 231.4 & 2D19 & 5D19 & 249.34 \\
\hline & & & Lapangan & 146.7 & 2D19 & 5D19 & 249.34 \\
\hline & \multirow{2}{*}{ B2 } & \multirow{2}{*}{$250 \times 400$} & Tumpuan & 55.52 & 2D16 & 4D16 & 86.27 \\
\hline & & & Lapangan & 38.82 & 2D16 & 4D16 & 86.27 \\
\hline \multirow{4}{*}{5} & \multirow{2}{*}{ B1 } & \multirow{2}{*}{$300 \times 600$} & Tumpuan & 205.4 & 2D19 & 5D19 & 249.34 \\
\hline & & & Lapangan & 150.1 & 2D19 & 5D19 & 249.34 \\
\hline & \multirow{2}{*}{ B2 } & \multirow{2}{*}{$250 \times 400$} & Tumpuan & 58.25 & 2D16 & 4D16 & 86.27 \\
\hline & & & Lapangan & 47.74 & 2D16 & 4D16 & 86.27 \\
\hline \multirow{6}{*}{ atap } & \multirow{2}{*}{ B3 } & \multirow{2}{*}{$150 \times 200$} & Tumpuan & 6.92 & 2D13 & 2D13 & 8.48 \\
\hline & & & Lapangan & 4.03 & 2D13 & 2D13 & 8.48 \\
\hline & \multirow{2}{*}{ RB 1} & \multirow{2}{*}{$200 \times 300$} & Tumpuan & 5.1 & 2D13 & 2D13 & 17.42 \\
\hline & & & Lapangan & 2.52 & 2D13 & 2D13 & 17.42 \\
\hline & \multirow{2}{*}{ RB 2} & \multirow{2}{*}{$150 \times 150$} & Tumpuan & 2.57 & $2 \varnothing 10$ & $2 \varnothing 10$ & 2.65 \\
\hline & & & Lapangan & 2.21 & $2 \varnothing 10$ & $2 \varnothing 10$ & 2.65 \\
\hline
\end{tabular}

Perencanaan Penulangan Pada Kolom (Tabel 3)

Diambil contoh kolom K1

Data-data perencanaan:

$\begin{array}{ll}\mathrm{f}^{\prime} \mathrm{c} & =25 \mathrm{Mpa} \\ \mathrm{fy} & =390 \mathrm{Mpa} \\ \beta 1 & =0,85 \\ \mathrm{~b} & =300 \mathrm{~mm} \\ \mathrm{~h} & =500 \mathrm{~mm} \\ \text { d sengkang } & =10 \mathrm{~mm} \\ \text { s beton } & =40 \mathrm{~mm}\end{array}$

Dari SAP2000 didapat Pu sebesar $=1.137,114 \mathrm{Kn}$ dan $\mathrm{Mu}=114,236 \mathrm{kNm}$

Hitung nilai eksentrisitas $\mathrm{e}=\quad \frac{M u}{P u}=\frac{114,236}{1137,114}=100,5 \mathrm{~mm}$

Karena $\mathrm{e}=100,5 \mathrm{~mm}<2 / 3 \mathrm{~d}=293,7 \mathrm{~mm}$, diasumsikan terjadi keruntuhan tekan.

Dicoba tulangan 6D19 $\rightarrow$ As $=6 \times 0,25 \times 3,14 \times 19^{2}=1.701 \mathrm{~mm}^{2}$ 
Nilai $\rho g=\frac{A s}{b \times h}=\frac{1701}{300 \times 600}=1,13 \%$; Nilai ini berada antara $1 \%$ sampai $8 \%$ yang merupakan syarat batas rasio tulangan memanjang kolom.

Perhitungan keruntuhan tekan dengan menggunakan rumus Whitney

$$
\begin{aligned}
& \mathrm{P}_{\mathrm{n}}=\left(\frac{\text { As } \times \text { fy }}{\frac{e}{d-d^{\prime}}+0,5}\right)+\left(\frac{b \times h \times f^{\prime} c}{\frac{3 \times h \times e}{d^{2}}+1,18}\right) \\
& \mathrm{P}_{\mathrm{n}}=\left(\frac{1701 \times 390}{\frac{100,5}{440,5-59,5}+0,5}\right)+\left(\frac{300 \times 500 \times 25}{\frac{3 \times 500 \times 100,5}{59,5^{2}}+1,18}\right) \\
& \mathrm{P}_{\mathrm{n}}=2.785,263 \mathrm{kN} \\
& \mathrm{M}_{\mathrm{n}}=\mathrm{P}_{\mathrm{n}} \times \mathrm{e}=2.785 \times 100,5=279,812 \mathrm{kNm} \\
& \varnothing \mathrm{P}_{\mathrm{n}}=\emptyset \times 2.785,263=1.810,421 \mathrm{kN}>\mathrm{Pu}=1.137,114 \mathrm{Kn} \\
& \varnothing \mathrm{M}_{\mathrm{n}}=\emptyset \times 279,812=181,877 \mathrm{kNm}>\mathrm{Mu}=114,236 \mathrm{kNm}
\end{aligned}
$$

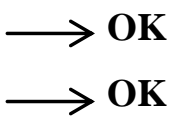

Untuk tulangan sengkang dipilih sengkang persegi berdiameter $10 \mathrm{~mm}$, syarat jarak maksimum tidak boleh melewati syarat dibawah ini :

- 48 kali diameter sengkang $=48 \times 10=480 \mathrm{~mm}$

- 16 kali diameter tulangan memanjang $=16 \times 19=304 \mathrm{~mm}$

- Dimensi terkecil penampang kolom $=500 \mathrm{~mm}$

Jadi diambil sengkang $\varnothing 10-100 \mathrm{~mm}$

Tabel 3. Hasil Analisis Dan Dimensi Tulangan Kolom

\begin{tabular}{ccccccc}
\hline $\begin{array}{c}\text { Type } \\
\text { Kolom }\end{array}$ & $\begin{array}{c}\text { Dimensi } \\
(\mathrm{mm})\end{array}$ & $\begin{array}{c}\mathrm{Mu} \\
(\mathrm{kNm})\end{array}$ & $\begin{array}{c}\mathrm{Pu} \\
(\mathrm{Kn})\end{array}$ & $\begin{array}{c}\text { Tulangan } \\
\text { Utama }\end{array}$ & $\begin{array}{c}\phi \mathrm{Mn} \\
(\mathrm{kNm})\end{array}$ & $\begin{array}{c}\phi \mathrm{Pn} \\
(\mathrm{kN})\end{array}$ \\
\hline $\mathrm{K} 1$ & $300 \mathrm{X}$ & 114.2 & 1137 & $6 \mathrm{D} 19$ & 181.8 & 1810. \\
& 500 & 4 & & & 8 & 4 \\
$\mathrm{~K} 2$ & $200 \mathrm{X}$ & 8.331 & 2 & $4 \mathrm{D} 13$ & 30.00 & 120.3 \\
& 200 & & 1.79 & & 9 & 9 \\
$\mathrm{KP}$ & $150 \mathrm{X}$ & 1.127 & 5 & $4 \mathrm{D} 10$ & 2 & 11.33 \\
\hline
\end{tabular}

\section{Metode Pelaksanaan}

Metode Pelaksanaan Kolom sesuai tahapan berikut:

1. Penentuan As kolom. Titik-titik as kolom diperoleh dari hasil pekerjaan pengukuran, yaitu marking berupa titik-titik atau garis yang digunakan sebagai dasar penentuan letak kolom.

2. Pemasangan tulangan kolom. Besi kolom dipasang sesuai dengan gambar shop drawing. Tentukan ukuran tulangan memanjang dan sengkang lalu potong menggunakan bar cutter dan bengkokkan menggunakan bar bender di lokasi pabrikasi.

3. Pemasangan sepatu kolom. Sepatu kolom digunakan untuk menjaga dimensi bekisting agar tidak bergeser akibat tekanan beton saat pengecoran. 
4. Pemasangan bekisting kolom. Pabrikasi bekisitng konvensional dilakukan dilos kerja kayu, Acuan bekisting kolom menggunakan plywood berukuran $12 \mathrm{~mm}$ yang dipotong selebar gambar kerja lalu dipasang 3 kayu ukuran 1x2 $\mathrm{cm}$ untuk pengaku acuan dan sabuk pengikat menggunakan kayu broti ukuran 5x7 cm yang disusun berlapis sesuai kebutuhan dilapangan.

5. Pengecoran kolom. Pengecoran beton dapat dilaksanakan setelah Kontraktor mendapat ijin secara tertulis dari Direksi/Pengawas Lapangan. Permohonan ijin rencana pengecoran harus diserahkan paling lambat 2 (dua) hari sebelumnya. Pembuatan adukan beton dengan campuran $1 \mathrm{pc}: 2 \mathrm{ps}$ : 3split dilakukan secara manual, dilakukan uji slump terlebih dahulu untuk mengetahui nilai kelecakan suatu beton segar, nilai slump yang dipakai berkisar 7,5 - $15 \mathrm{~cm}$.

6. Pembongkaran bekisting kolom. Pembongkaran bekisting dapat dilakukan minimal 3 (tiga) hari setelah konstruksi dicor atau harus seijin Direksi/Pengawas Lapangan/Tim Pengelola Teknis Kegiatan dan dilaksanakan sedemikian rupa sehingga menjamin keamanan sepenuhnya.

Metode Pelaksanaan Balok sebagai berikut:

1. Pemasangan perancah bamboo. Perancah berbentuk $\mathrm{T}$ menggunakan bambu/kayu dan balok surisuri berukuran $5 \times 7 \mathrm{~cm}$ beserta perlengkapannya berjarak $\pm 50 \mathrm{~cm}$. Pemasangannya harus benarbenar kokoh dan tidak berubah tempat sebelum dan selama pengecoran.

2. Pemasangan papan bodeman. Pemasangan bodeman untuk setting elevasi balok serta dudukan tulangan saat dimulainya perakitan tulangan balok.

3. Pemasangan tembereng dan siku bekisting. Memasang tembereng/dinding bekisting balok yang dibuat dari kayu kelas II tebal $3 \mathrm{~cm}$ dan plywood $12 \mathrm{~mm}$ dengan permukaan yang rata dan diketam halus diatas balok suri-suri kemudian dikakukan menggunakan siku kayu.

4. Pemasangan tulangan balok. Besi balok dipasang sesuai dengan gambar shop drawing. Tentukan ukuran tulangan memanjang dan sengkang lalu potong menggunakan bar cutter dan bengkokan menggunakan bar bender di lokasi pabrikasi.

5. Pengecoran balok. Pengecoran beton dapat dilaksanakan setelah Kontraktor mendapat ijin secara tertulis dari Direksi/Pengawas Lapangan. Permohonan ijin rencana pengecoran harus diserahkan paling lambat 2 (dua) hari sebelumnya. bersihkan area yang akan dicor menggunakan compressor, lakukan uji slump, nilai slump yang dipakai berkisar 7,5-15 cm. Cetak benda uji untuk pemeriksaan mutu, tuang beton segar ke dalam bekisting balok, lalu padatkan dengan menggunakan mesin vibrator.

6. Pembongkaran bekisting balok. Pembongkaran bekisting dapat dilakukan minimal 3 (tiga) hari setelah konstruksi dicor atau harus seijin Direksi/Pengawas Lapangan/Tim Pengelola Teknis Kegiatan dan dilaksanakan sedemikian rupa sehingga menjamin keamanan sepenuhnya.

7. Perawatan beton balok. Perawatan ini dilakukan setelah beton mencapai final setting, artinya beton telah mengeras. Perawatan ini dilakukan untuk menjaga mutu beton. Perawatan beton yang dilakukan adalah menyiram beton dengan air dua kali sehari selama seminggu 


\section{SIMPULAN}

Hasil akhir analisis dari program komputer SAP2000 v.14 menunjukkan bahwa struktur balok dan kolom cukup aman untuk memikul beban mati, hidup, angin dan gempa. Dari hasil perencanaan didapat dimensi dan jumlah tulangan yang sudah memenuhi persyaratan, dimana untuk balok $\emptyset \mathrm{Mn}>\mathrm{Mu}$, dan untuk kolom $\emptyset \mathrm{Mn}>$ $\mathrm{Mu}, \varnothing \mathrm{Pn}>\mathrm{Pu}$. Metode pelaksanaan yang dilakukan pada pekerjaan kolom dan balok telah sesuai dengan standar metode pelaksanaan pekerjaan struktur. Pada pekerjaan balok dan kolom proyek pembangunan Gedung Kantor APD (Area Pengatur Distribusi) PLN ini menggunakan acuan dan perancah sistem konvensional. Sistem ini terlihat dengan digunakannya plywood dengan ketebalan $12 \mathrm{~mm}$ dan perancah bambu. Pengecoran balok dan kolom menggunakan beton dengan mutu K-300 (f'c 25) dan nilai slump 7,5-15 cm. Pembongkaran bekisting pada balok dan kolom dapat dilakukan minimal 3 (tiga) hari setelah konstruksi dicor atau harus seijin Direksi/Pengawas Lapangan/Tim Pengelola Teknis Kegiatan.

\section{DAFTAR PUSTAKA}

Asroni, Ali. (2010). Balok dan Plat Beton Bertulang. Yogyakarta: Graha Ilmu.

Alberto. (2019). Perencanaan Ulang Balok Dan Kolom Struktur Beton Bertulang Dengan Program Komputer Sap2000 V.14 Pada Proyek Vihara Mahasampatti. Medan: Politeknik Negeri Medan

Badan Standarisasi Nasional. (2012). Tata Cara Perencanaan Ketahanan Gempa untuk Bangunan Gedung SNI 1726:2012. Jakarta.

Badan Standarisasi Nasional. (2013). Beban Minimum untuk Perancangan Bangunan Gedung dan Struktur Lain SNI 1727:2013. Jakarta.

Badan Standarisasi Nasional. (2013). Persyaratan Beton Struktural Untuk Bangunan Gedung SNI 2847:2013. Jakarta.

Setiawan, Agus. (2016). Perancangan Struktur Beton Bertulang Berdasarkan SNI 2847 : 2013. Jakarta: Erlangga. 